\title{
Nickel-Catalyzed Reversible Functional Group Metathesis between Aryl Nitriles and Aryl Thioethers
}

\section{Journal Article}

Author(s):

Delcaillau, Tristan; Boehm, Philip; Morandi, Bill

Publication date:

2021-03-17

Permanent link:

https://doi.org/10.3929/ethz-b-000476419

Rights / license:

Creative Commons Attribution-NonCommercial-NoDerivatives 4.0 International

Originally published in:

Journal of the American Chemical Society 143(10), https://doi.org/10.1021/jacs.1c00529

\section{Funding acknowledgement:}

184658 - Catalytic synthesis of unprotected amines and heterocycles (SNF)

757608 - Shuttle Catalysis for Reversible Molecular Construction (EC) 


\title{
Nickel-Catalyzed Reversible Functional Group Metathesis between Aryl Nitriles and Aryl Thioethers
}

\author{
Tristan Delcaillau, Philip Boehm, and Bill Morandi*
}

Cite This: J. Am. Chem. Soc. 2021, 143, 3723-3728

Read Online

ABSTRACT: We describe a new functional group metathesis between aryl nitriles and aryl thioethers. The catalytic system nickel/ dcype is essential to achieve this fully reversible transformation in good to excellent yields. Furthermore, the cyanide- and thiol-free reaction shows high functional group tolerance and great efficiency for the late-stage derivatization of commercial molecules. Finally, synthetic applications demonstrate its versatility and utility in multistep synthesis.

$\mathrm{A}^{\mathrm{n}}$ ryl nitriles and aryl thioethers are often found in biologically active molecules such as natural products, pharmaceuticals, fragrances, and agrochemicals. ${ }^{1-4}$ Notably, these two functional groups are complementary in terms of their reactivity and directing ability for aromatic functionalization chemistry. The $\mathrm{CN}$ group is a traditional electronwithdrawing group that deactivates an aromatic ring and directs electrophilic aromatic substitution to the meta position. ${ }^{5,6}$ In contrast, aryl thioethers are relatively electronneutral substituents which facilitate these reactions at the para position. $^{7-9}$ Moreover, while cyanides are common precursors to carboxylic acids, ketones and amines, aryl thioethers are precursors to a wide range of important sulfur-containing products and can be used as handles for directed metalation reactions. $^{10-12}$ Many efforts have been realized to further transform aryl nitriles and aryl thioethers into other functional groups. ${ }^{13-20}$ In light of the inherent orthogonality and complementarity of these two important functional groups, the development of efficient methods to interconvert them is an important goal in target-oriented synthesis (Scheme 1A).

Traditionally, these two classes of important products have been accessed from conventional aryl halide electrophiles using cyanide salts or thiols (Scheme 1B). ${ }^{21-27}$ Because of the inconvenient nature of these reagents, such as high toxicity in the case of cyanide salts and low-molecular-weight thiols, researchers have tried to develop suitable alternatives. Recently, to avoid traditional metal cyanide reagents and classical toxic sources such as TMSCN and acetone cyanohydrin, ${ }^{28-30}$ the development of less-toxic organic nitriles has emerged as an attractive alternative. Selected examples include the use of $\mathrm{MeCN}$, butyronitrile and 2methyl-2-phenylmalononitrile. ${ }^{31-34}$ With regard to thiols, Walsh and co-workers have described an elegant access to functionalized diaryl thioethers via a debenzylative pathway between aryl benzyl sulfides and aryl bromides. ${ }^{35}$ More recently, an example of aryl thioether formation using an aliphatic thioether as a formal thiol donor has been reported by $\mathrm{Wu}$ and co-workers. ${ }^{36}$ Overall, while these methods provide useful and safer alternatives to the common cyanide and thiol reagents, they do follow a classical cross-coupling paradigm

\section{Scheme 1. Context of the Work}

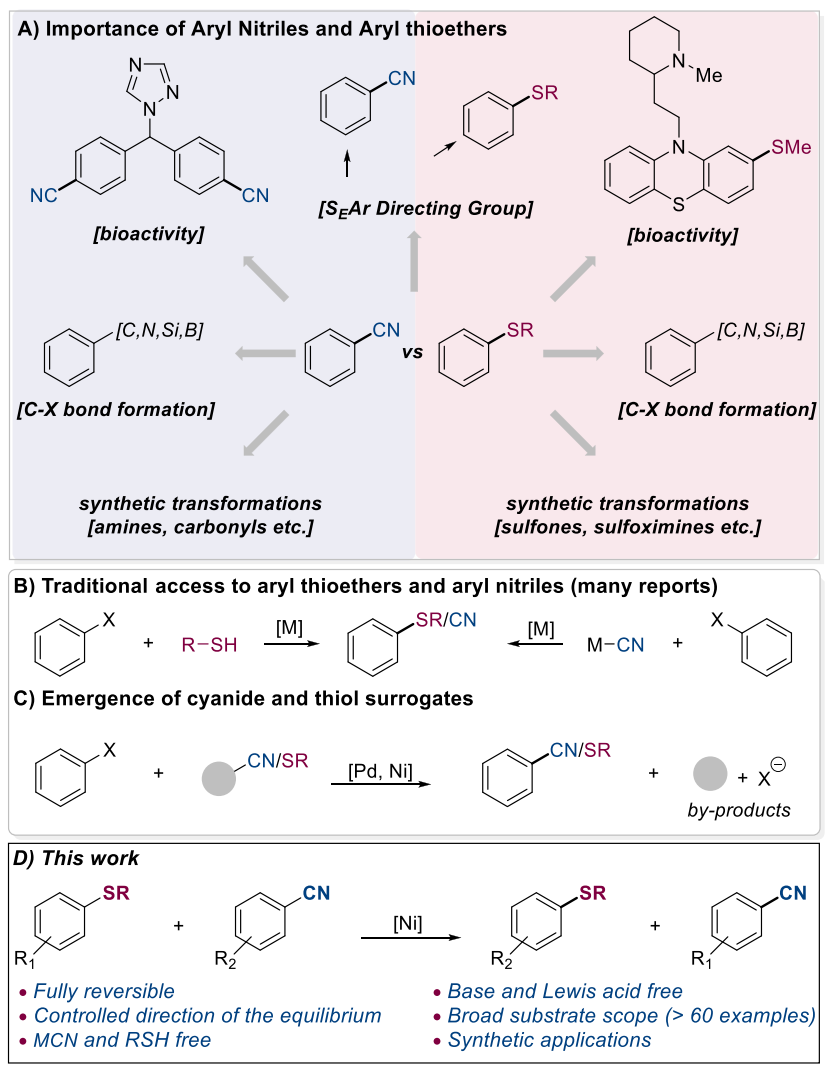

proceeding through the irreversible coupling of aryl halide electrophiles. (Scheme 1C).

Received: January 15, 2021

Published: March 3, 2021 
Table 1. Scope with Respect to Aryl Thioethers ${ }^{a}$

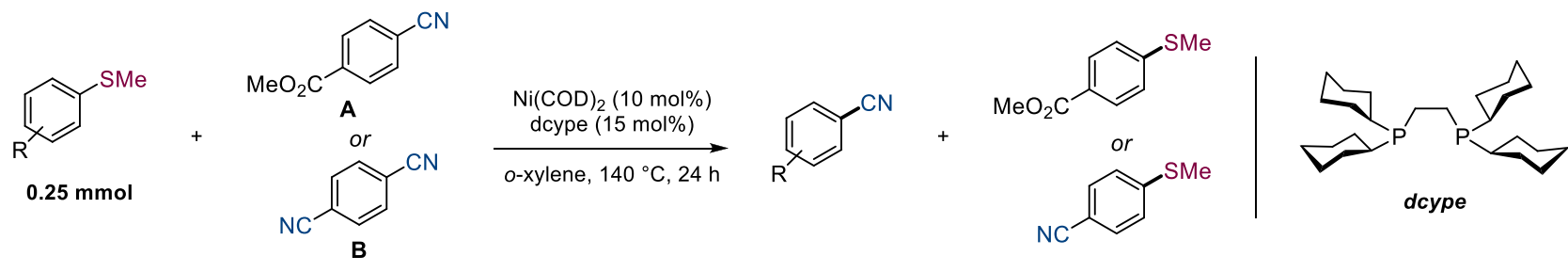

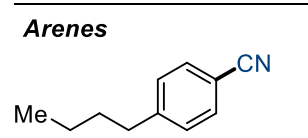

$3 a, 77 \%$<smiles>COc1cc(C#N)cc(OC)c1</smiles>

$3 g, 89 \%$<smiles>N#Cc1cccc(F)c1</smiles>

$3 \mathrm{~m}, 80 \%{ }^{\mathrm{c}}$<smiles>Cc1ccc(C#N)cc1C</smiles>

3b, $63 \%$<smiles>CC(C)(C)c1ccc(C#N)cc1</smiles>

$3 c, 71 \%$<smiles>N#Cc1ccc(-c2ccccc2)cc1</smiles>

$3 d, 94 \%$<smiles>COc1ccc(C#N)cc1</smiles>

$3 e, 56 \%$<smiles>N#Cc1ccc(Oc2ccccc2)cc1</smiles>

3f, $88 \%$<smiles>COc1cc(C#N)cc(OC)c1OC</smiles><smiles>CC(C)=CCCC(C)CCOc1ccc(C#N)cc1</smiles><smiles>COc1ccccc1C#N</smiles><smiles>N#Cc1ccccc1F</smiles>

$31,85 \%{ }^{c}$<smiles>N#Cc1ccc2ccccc2c1</smiles>

$3 r, 88 \%$<smiles>N#Cc1cccc2ccccc12</smiles>

3s, $37 \%$<smiles>N#Cc1ccc(C(=O)N2CCOC2)cc1</smiles>

3 n, $50 \%{ }^{b}$<smiles>CC(=O)c1cccc(C=[N+]=[N-])c1</smiles>

3o, $86 \%^{b}$<smiles>[13CH3]OC(=O)c1cccc(C#N)c1</smiles>

$3 p, 68 \%^{b}$<smiles>Nc1cccc([SH](=O)(O)O[Mg])c1</smiles>

$3 q, 86 \%^{b}$

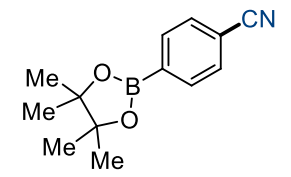

3w, $70 \%(81 \%)^{\mathrm{c}}$<smiles>N#Cc1ccc(CN2C(=O)c3ccccc3C2=O)cc1</smiles>

$3 v, 57 \%^{c}$

$3 u, 83 \%^{b}$<smiles>C=Cc1ccc(C#N)cc1</smiles>

3t, $95 \%$<smiles>CCCC(=O)N(Cc1ccccc1)c1ccc(C#N)cc1</smiles><smiles>N#Cc1ccc2oc3ccccc3c2c1</smiles>

3aa, $94 \%$

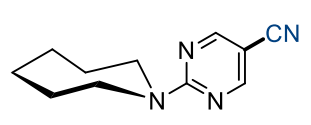

$3 a b, 81 \%$ Commercially relevant arenes<smiles>N#Cc1ccc2c(c1)Nc1ccccc1S2</smiles>

3ac, $54 \%$

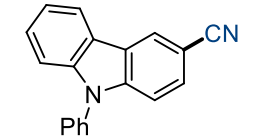

3ad, $40 \%$

3y, $73 \%^{\mathrm{c}}$

$3 z, 82 \%$<smiles>N#Cc1ccc(OCC23CC(CO2)C3)cc1</smiles>

3ag, $91 \%$<smiles>CC(C)(C(=O)c1ccc(C#N)cc1)N1CCOCC1</smiles>

MMMP derivative 3ah, $94 \%^{\mathrm{b}}$<smiles>Cn1ccnc1COc1ccc(C#N)cc1</smiles>

Fexinidazole derivative 3ai, $32 \%$<smiles>Cc1ccc(-c2cc(C(F)(F)F)nn2-c2ccc(C#N)cc2)cc1</smiles>

Celecoxib derivative 3aj, $86 \%$ 3af, $40 \%$

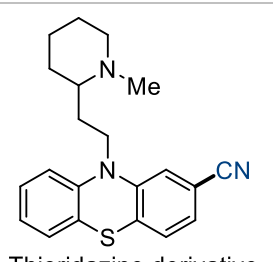

3ak, $78 \%{ }^{\text {b,d }}$<smiles></smiles>

Letrozole $3 \mathrm{al}, 63 \%(+20 \% \text { of mono } \mathrm{CN})^{\mathrm{b}}$<smiles>Cc1cc(C)c2c(c1)CCC(C)(CCCC(C)CCC[C@H](C)CCCC(C)C)O2</smiles>

(+)- $\delta$-Tocopherol derivative 3am, 51\%

${ }^{a}$ Yield of isolated product. ArSMe (0.25 mmol), donor A (2.0 equiv), Ni(COD) 2 (10 mol \%), dcype (15 mol \%), o-xylene $(0.25 \mathrm{M}), 140{ }^{\circ} \mathrm{C}, 24 \mathrm{~h}$. ${ }^{b}$ Donor $\mathbf{B}$ (2.0 equiv) was used. ${ }^{c} \mathrm{NMR}$ yield. ${ }^{d}$ The $\mathrm{HCl}$ salt was used with LiHMDS (1.1 equiv).

In 2018, Arndtsen's group and our group independently reported a distinct approach to cross-coupling reactions proceeding through the reversible metathesis of two electrophiles, acid chlorides and aryl iodides. ${ }^{37-39}$ This new class of reactions effectively provides a means to interconvert, at will, these functional groups using a single catalytic system. Subsequently, Yamaguchi and co-workers elegantly used this concept to transfer an ester moiety to several aryl (pseudo)halides. ${ }^{40}$ We wondered whether a functional group metathesis approach could be applied to completely different classes of functional groups, such as aryl cyanides and thioethers. If such a transformation could be realized, then it would not only provide a unique way to interconvert these two orthogonal functional groups in a cyanide and thiol-free manner, but 
would also considerably expand the scope of the emerging class of single-bond metathesis reactions (Scheme 1D).

On the basis of the recent success in activating both $\mathrm{C}-\mathrm{CN}$ and C-SR bonds under nickel catalysis, ${ }^{41-47}$ we reasoned that a Ni-based catalytic manifold could provide an appropriate platform to develop this reaction. However, two main challenges were identified: (1) a single catalyst and set of reaction conditions need to be competent for two distinct and reversible oxidative additions; (2) a suitable transfer mechanism, such as a direct crossover between two oxidative addition complexes, needs to be kinetically accessible. We initially explored this process by evaluating a range of ligands, in combination with a $\mathrm{Ni}(\mathrm{COD})_{2}$ precatalyst, for the metathesis between thioanisole and 4-methylbenzonitrile. Traces of 4-methylthioanisole and benzonitrile were observed by employing 1,2-bis(dicyclohexylphosphino)ethane (dcype) as a ligand (details in the SI), which has been shown previously to enable the activation and the formation of $\mathrm{C}-\mathrm{SR}$ and $\mathrm{C}-$ $\mathrm{CN}$ bonds. ${ }^{45,48-50}$ After an extensive study (details in the SI), $\mathrm{Ni}(\mathrm{COD})_{2}(10 \mathrm{~mol} \%)$ and a slight excess of dcype (15 mol $\%$ ) in $o$-xylene at $140{ }^{\circ} \mathrm{C}$ for $24 \mathrm{~h}$ were found to be most effective at reaching the equilibrium of the reaction, namely, to get the same product distribution in the forward and reverse reactions.

We next investigated different nitrile donors to find suitable conditions to shift the equilibrium of this reversible and thermodynamically controlled reaction toward the product $(\mathrm{Ar}-\mathrm{CN})$ side. We reasoned that an electronic mismatch could serve as a potent driving force for the reaction. ${ }^{39}$ For electron-neutral and -rich aryl thioether acceptors, 2.0 equiv of methyl 4-cyanobenzoate (donor A) were competent to achieve the transformation in high yield, whereas for electron-poor aryl thioethers, 2.0 equiv of 1,4-dicyanobenzene (donor B) were employed. We next explored the scope of the reaction (Table 1). To our delight, a wide range of thioanisole derivatives worked efficiently under the reaction conditions. Indeed, both electron-neutral and electron-rich substrates $(\mathbf{3} \mathbf{a}-\mathbf{3 i})$ worked well, affording the corresponding products in good to excellent yield (56-94\%). A citronellol-based ether, bearing an alkene that could possibly deactivate the catalyst through coordination, afforded the expected product $(3 \mathbf{j})$ in $76 \%$ yield. ${ }^{51}$ Sterically hindered aryl thioethers bearing an ortho substituent (3k and $3 \mathbf{l}$ ) also proved to be competent partners in affording the desired product in 56 and $85 \%$ yields, respectively. We then applied the optimal conditions by using the other donor, 1,4-dicyanobenzene (donor B), to different electron-poor thioanisoles. Gratifyingly, many electron-withdrawing functional groups, such as fluoride $(\mathbf{3 m})$, amide $(3 \mathbf{n})$, ketone (3o), ester $(3 \mathbf{p})$, and sulfone $(\mathbf{3 q})$, were tolerated. In all cases, the desired product was obtained in moderate to excellent yield (50-87\%). Bicyclic compounds such as 2- and 1-naphthyl derivatives ( $3 \mathbf{r}$ and $3 \mathbf{s}$ ) reacted smoothly under the reaction conditions ( 88 and $37 \%)$. We then successfully subjected several arenes bearing common functional groups, including acetal (3t), benzyl-protected amide (3u), vinyl (3v), pinacol boronic ester $(3 \mathbf{w})$, and phthalimide-protected amine $(\mathbf{3 x})$, to our reaction. Furthermore, several heterocycles, such as a thiophene (3y), a benzofuran (3z), a dibenzofuran (3aa), a pyrimidine bearing an azepane moiety ( $3 \mathrm{ab})$, a phenothiazine possessing a free aniline ( $3 \mathrm{ac}$ ), a carbazole (3ad), which is an important class of compounds in organic electronics, ${ }^{52}$ a quinolone (3ae), and a 1,3,4-oxadiazole (3af), all afforded the metathesis product in moderate to excellent yield (40-94\%).
We also applied this methodology to a thioanisole bearing a 2oxabicyclo[2.1.1] hexane moiety (3ag), which was recently shown to be a water-soluble bioisostere of benzene. ${ }^{53}$ Gratifyingly, the expected nitrile product was obtained in excellent yield (91\%).

Finally, we subjected several commercially relevant molecules to the reaction conditions. To our delight, the late-stage derivatization of photoinitiator MMMP $(3 \mathrm{ah})^{54}$ and fexinidazole (3ai), a drug used to treat sleeping sickness, ${ }^{55}$ proceeded smoothly. Furthermore, the synthesis of the nitrile derivative of celecoxib (3aj), a COX-2 inhibitor, ${ }^{56}$ and the late-stage derivatization of thioridazine (3ak) were successfully achieved. We could also access a drug used in the treatment of breast cancer, letrozole (3al), ${ }^{57}$ in an efficient way (63\% yield), showing the possibility to transfer two cyanides in a single-step protocol. We finally synthesized a derivative of $\delta$-tocopherol (3am) with this catalytic manifold in a synthetically useful yield of $51 \%$.

The reverse reaction (i.e., the conversion of an aryl nitrile to an aryl thioether) was next explored (Table 2). We found that both 4-methoxythioanisole (donor C) and 4-morpholinethioanisole (donor $\mathbf{D}$ ) were suitable donors for this reaction due to their electron-donating properties that thermodynamically favor the donation of the SMe group. Similar to the forward reaction, the functional group tolerance proved to be high. Indeed, thioanisoles bearing an alkyl (4a), trifluoromethyl (4b), difluoro (4c), sulfone (4d), amide (4e), ketone (4f), ester (4g), or cyano (4h) group were obtained in good to quantitative yield (60-99\%). Several heterocycles and bicycles, such as quinoline (4i), pyridine (4j), 1,3,4-oxadiazole (4k), benzothiophene (4l), and 2-naphtalene $(4 \mathrm{~m})$, worked in modest to excellent yield (26-86\%). Furthermore, menthol (4n), a fluorine-containing substrate $(4 p)$, proline $(4 q)$, and cholesterol derivatives (4r) were all found to be competent partners. Notably, an aryl nitrile bearing an alkyl nitrile (4o) worked smoothly under the reaction conditions, confirming that aliphatic carbon-cyanide bonds do not react with nickel in the absence of Lewis acids. ${ }^{58}$ We next explored the substrate scope of alkyl thioethers. To our delight, thioethers bearing either an ethyl (4s), an alkyl nitrile (4t), an alkyl $\mathrm{CF}_{3}(4 \mathbf{u})$, or an azetidine $(\mathbf{4 v})$ group were efficiently transferred to the metathesis products in moderate to excellent yield (41-96\%). A derivative of probenecid $(4 \mathrm{w})$ was successfully obtained in $95 \%$ yield, as well as the late-stage derivatized fadrozole $(4 \mathbf{x}$, $62 \%)$. Finally, the synthesis of widely used photoinitiator MMMP (4y) was performed, affording the desired product in good yield $(74 \%) .^{52}$

Inspired by Yamaguchi and co-workers' recent work, the ester dance on an aromatic ring, ${ }^{59}$ we explored the possibility of scrambling the cyano and thioether groups located on a single substrate (Scheme 2A). We thus subjected starting material 5a, bearing one electron-rich and one electron-poor aromatic ring, to the optimized conditions to obtain the clean formation of three new products in addition to the starting material. Gratifyingly, we were able to separate the four different compounds which were further characterized. This result shows the potential of this methodology to generate a library of derivatives through late-stage nitrile/thioether metathesis diversification.

We next turned our attention to the intrinsic electronic properties of both functional groups and their influence on Friedel-Crafts acylation (Scheme 2B). The thioether group usually directs the reaction to the para position, ${ }^{7-9}$ while the 
Table 2. Scope with Respect to Aryl Nitriles ${ }^{a}$

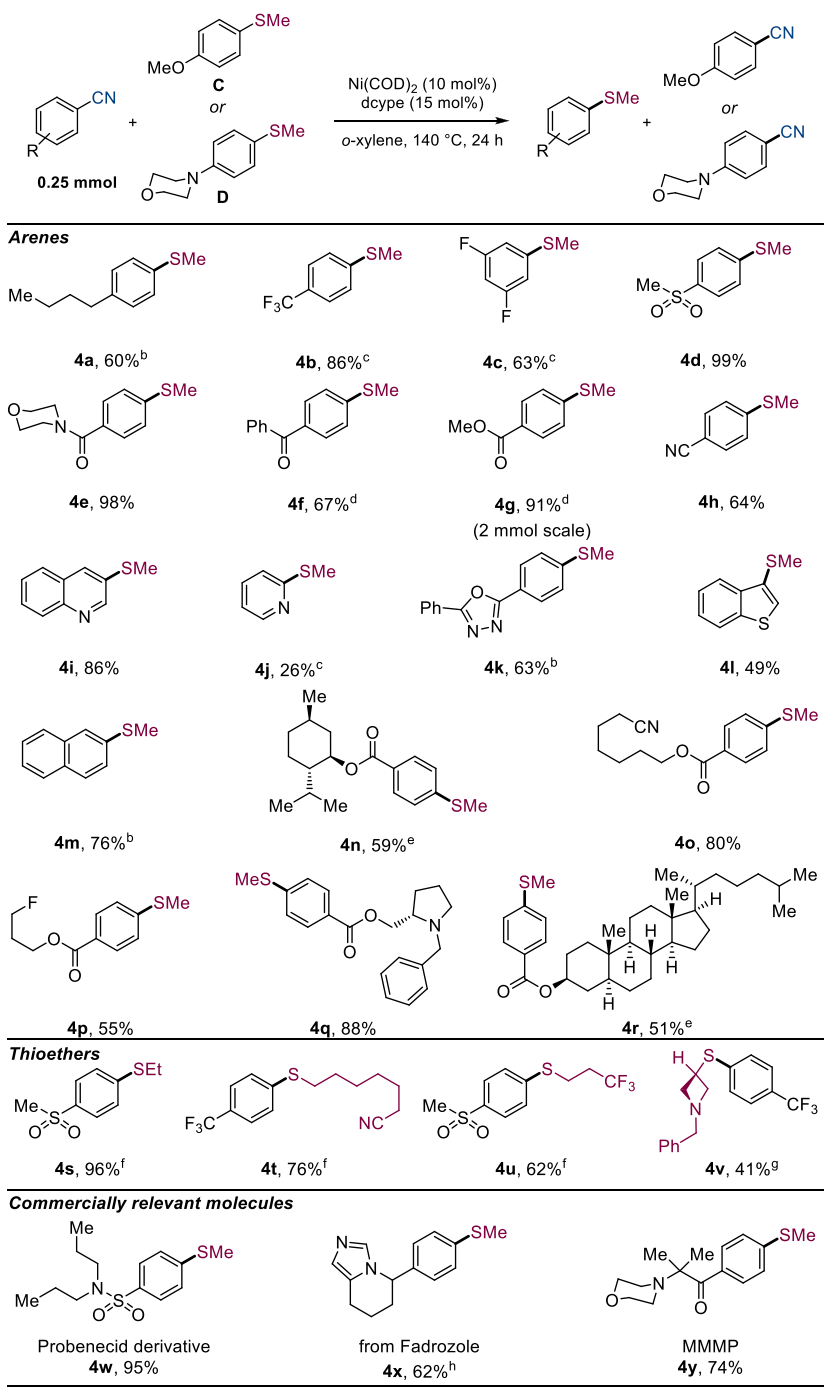

${ }^{a}$ Yield of isolated product. $\operatorname{ArCN}(0.25 \mathrm{mmol})$, donor $\mathrm{C}$ (3.0 equiv), $\mathrm{Ni}(\mathrm{COD})_{2}(10 \mathrm{~mol} \%)$, dcype (15 mol \%), o-xylene (0.25 M), 140 ${ }^{\circ} \mathrm{C}, 24$ h. ${ }^{b}$ Donor $\mathbf{D}$ (3.0 equiv) was used. ${ }^{c}$ NMR yield. ${ }^{d}$ Isolated as an alcohol after reduction. ${ }^{e}$ Isolated as sulfone after oxidation. $f_{2.0}$ equiv of the respective $\mathrm{MeO}-\mathrm{Ph}-\mathrm{SR}$ donor. ${ }^{g} 1.0$ equiv of the respective $\mathrm{MeO}-\mathrm{Ph}-\mathrm{SR}$ donor. ${ }^{h}$ The $\mathrm{HCl}$ salt was used with LiHMDS (1.1 equiv). For details, see the SI.

deactivating electron-withdrawing nitrile directs the reaction to the meta position. ${ }^{5,6}$ By subjecting 3-methylthioanisole to a mixture of butyryl chloride and aluminum chloride, $63 \%$ of the desired ketone product (6a) was isolated. Interestingly, the same set of conditions did not lead to any conversion using 3methylbenzonitrile, and no product was observed even under more forcing conditions, confirming the strong deactivating effect of this group (details in the SI). We could then successfully transform the thioanisole derivative to aryl nitrile $\mathbf{6 b}$ in $71 \%$ yield, thus highlighting the possibility to synthesize densely substituted aromatic products with challenging substitution patterns.

Nitrile and thioether groups have orthogonal chemical reactivity. The former is tolerant to oxidative conditions but nontolerant to reductive ones, which is the exact opposite for thioethers. This complementary behavior offers strategic opportunities for target-oriented synthesis. In this context,
Scheme 2. Synthetic Applications ${ }^{a}$
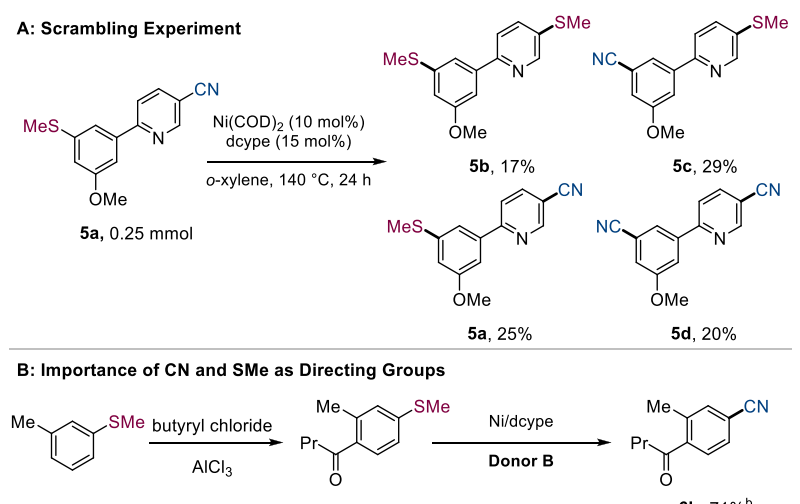

$6 \mathbf{a}, 63 \%$
from $m-M e-P h C N$ : no reaction

$6 b, 71 \%^{\mathrm{b}}$

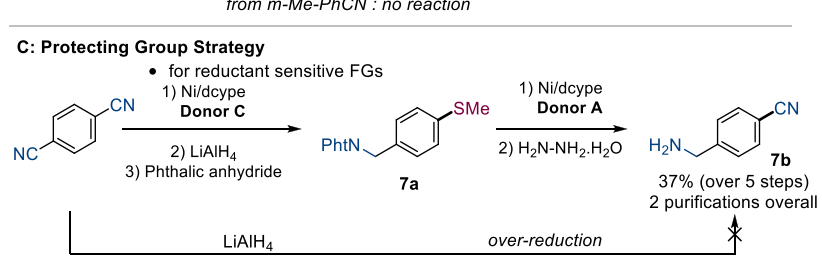

- for oxidant sensitive FGs

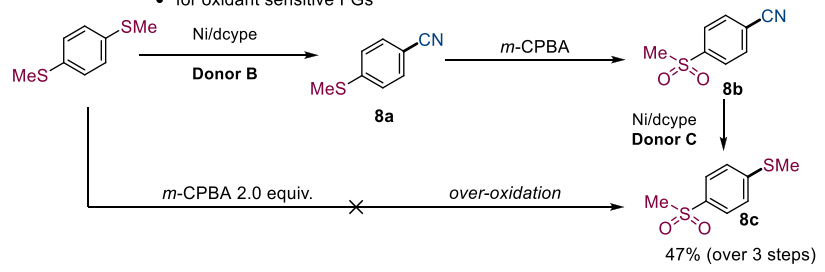

${ }^{a}$ Yield of isolated product (\%). ${ }^{b}$ Isolated as an alcohol after reduction. For details, see the SI.

the reversibility of our metathesis reaction can be harnessed as a useful protecting group strategy for cyanides and thioethers. Our initial idea was to protect a nitrile group as a thioether to perform a selective reduction (Scheme 2C). The selectively monoreduced product $(7 \mathbf{b})$ was obtained in a synthetically useful yield of $37 \%$ over five steps, with only two purifications. We next transiently protected a thioether group as a nitrile to perform an oxidation process (Scheme 2C). Using this strategy, the mono-oxidized product was obtained in $47 \%$ yield over three steps. These results clearly show the potential of this new metathesis reaction to overcome conventional synthetic challenges through a new kind of protecting group strategy.

In conclusion, we have developed a functional group metathesis between aryl nitriles and aryl thioethers under nickel catalysis. This transformation does not require any cyanide or thiol reagents, making it a convenient alternative to traditional cross-coupling reactions. Late-stage derivatization of commercial molecules further demonstrated the synthetic potential of the transformation. In a broader context, this new example of functional group metathesis significantly expands the scope of this emerging class of reactions.

\section{ASSOCIATED CONTENT}

SI Supporting Information

The Supporting Information is available free of charge at https://pubs.acs.org/doi/10.1021/jacs.1c00529.

Experimental details for all reactions and analytic details for all products $(\mathrm{PDF})$ 


\section{AUTHOR INFORMATION}

\section{Corresponding Author}

Bill Morandi - ETH Zürich, 8093 Zürich, Switzerland; ○ orcid.org/0000-0003-3968-1424; Email: bill.morandi@ org.chem.ethz.ch

\section{Authors}

Tristan Delcaillau - ETH Zürich, 8093 Zürich, Switzerland Philip Boehm - ETH Zürich, 8093 Zürich, Switzerland

Complete contact information is available at: https://pubs.acs.org/10.1021/jacs.1c00529

Notes

The authors declare no competing financial interest.

\section{ACKNOWLEDGMENTS}

We thank the Swiss National Science Foundation (SNSF 184658), the European Research Council (ERC Starting Grant 757608 ShuttleCat), and ETH Zürich for financial support. We also acknowledge the NMR service and the Molecular and Biomolecular Analysis Service (MoBiAS) for technical assistance. We also thank Yong Ho Lee for insightful discussions, Eric Falk for NMR analysis, Sven Roediger for preliminary DFT studies and Ori Green for preparative HPLC purification. P.B. thanks the FCI for a scholarship.

\section{REFERENCES}

(1) Kleemann, A.; Engel, J.; Kutscher, B.; Reichert, D. Pharmaceutical Substance: Synthesis, Patents and Applications of The Most Relevant AIPs, 5th ed.; Thieme: Stuttgart, 2008; pp 1-1800.

(2) Dunbar, K. L.; Scharf, D. H.; Litomska, A.; Hertweck, C. Enzymatic Carbon-Sulfur Bond Formation in Natural Product Biosynthesis. Chem. Rev. 2017, 117, 5521-5577.

(3) Schoenauer, S.; Schieberle, P. Structure-Odor Activity Studies on Monoterpenoid Mercaptans Synthesized by Changing the Structural Motifs of the Key Food Odorant 1-p-Menthene-8-Thiol. J. Agric. Food Chem. 2016, 64, 3849-3861.

(4) Rosenman, A.; Markevich, E.; Salitra, G.; Aurbach, D.; Garsuch, A.; Chesneau, F. F. Review on Li-Sulfur Battery Systems: An Integral Perspective. Adv. Energy Mater. 2015, 5, 1500212.

(5) Gu, X.-L.; Liu, H.-B.; Jia, Q.-H.; Li, J.-F.; Liu, Y.-L. Design and Synthesis of Novel Miconazole-Based Ciprofloxacin Hybrids as Potential Antimicrobial Agents. Monatsh. Chem. 2015, 146, 713-720.

(6) Hammond, G. S.; Douglas, K. J.; Hammond, G. S.; Douglas, K. J. Aromatic Nitration. III. The ortho to para Ratio in Nitration of Benzonitrile. J. Am. Chem. Soc. 1959, 81, 1184-1187.

(7) Liu, G. Z.; Xu, H. W.; Wang, P.; Lin, Z. T.; Duan, Y. C.; Zheng, J. X.; Liu, H. M. Stereoselective Synthesis and Anti-Proliferative Effects on Prostate Cancer Evaluation of 5-Substituted-3,4-Diphenylfuran-2-Ones. Eur. J. Med. Chem. 2013, 65, 323-336.

(8) Reddy, V. P.; Prakash, G. K. S. Kirk-Othmer Encyclopedia of Chemical Technology; John Wiley \& Sons: Hoboken, NJ, 2013; pp 149.

(9) Hansch, C.; Leo, A.; Taft, R. W. A Survey of Hammett Substituent Constants and Resonance and Field Parameters. Chem. Rev. 1991, 91, 165-195.

(10) Rappoport, Z. Chemistry of The Cyano Group; John Wiley \& Sons: London, 1970: pp 1-1044.

(11) Barbero, N.; Martin, R. Ligand-Free Ni-Catalyzed Reductive Cleavage of Inert Carbon - Sulfur Bonds. Org. Lett. 2012, 14, 796799.

(12) Modha, S. G.; Van der Eycken, E. V.; Mehta, V. P. Transition Metal-Catalyzed $\mathrm{C}-\mathrm{C}$ Bond Formation via $\mathrm{C}-\mathrm{S}$ Bond Cleavage: An Overview. Chem. Soc. Rev. 2013, 42, 5042-5055.

(13) Dorval, C.; Tricoire, M.; Begouin, J. M.; Gandon, V.; Gosmini, C. Cobalt-Catalyzed $\mathrm{C}\left(\mathrm{sp}^{2}\right)-\mathrm{CN}$ Bond Activation: Cross-Electro- phile Coupling for Biaryl Formation and Mechanistic Insight. ACS Catal. 2020, 10, 12819-12827.

(14) Miller, J. A.; Dankwardt, J. W.; Penney, J. M. Nickel Catalyzed Cross-Coupling and Amination Reactions of Aryl Nitriles. Synthesis 2003, 2003, 1643-1648.

(15) Tobisu, M.; Kita, Y.; Ano, Y.; Chatani, N. Rhodium-Catalyzed Silylation and Intramolecular Arylation of Nitriles via the SiliconAssisted Cleavage of Carbon-Cyano Bonds. J. Am. Chem. Soc. 2008, 130, 15982-15989.

(16) Tobisu, M.; Kinuta, H.; Kita, Y.; Rémond, E.; Chatani, N. Rhodium(I)-Catalyzed Borylation of Nitriles through the Cleavage of Carbon-Cyano Bonds. J. Am. Chem. Soc. 2012, 134, 115-118.

(17) Zhu, D.; Shi, L. Ni-Catalyzed Cross-Coupling of Aryl Thioethers with Alkyl Grignard Reagents via C-S Bond Cleavage. Chem. Commun. 2018, 54, 9313-9316.

(18) Delcaillau, T.; Bismuto, A.; Müller, P.; Morandi, B. NickelCatalyzed Amination of Aryl Thioethers: A Combined Synthetic and Mechanistic Study. ACS Catal. 2020, 10, 4630-4639.

(19) Uetake, Y.; Niwa, T.; Hosoya, T. Rhodium-Catalyzed IpsoBorylation of Alkylthioarenes via $\mathrm{C}-\mathrm{S}$ Bond Cleavage. Org. Lett. 2016, 18, 2758-2761.

(20) Auvinet, A. L.; Harrity, J. P. A.; Hilt, G. Ambient-Temperature Cobalt-Catalyzed Cycloaddition Strategies to Aromatic Boronic Esters. J. Org. Chem. 2010, 75, 3893-3896.

(21) Kim, K.; Hong, S. H. Photoinduced Copper(I)-Catalyzed Cyanation of Aromatic Halides at Room Temperature. Adv. Synth. Catal. 2017, 359, 2345-2351.

(22) Neetha, M.; Afsina, C. M. A.; Aneeja, T.; Anilkumar, G. Recent Advances and Prospects in the Palladium-Catalyzed Cyanation of Aryl Halides. RSC Adv. 2020, 10, 33683-33699.

(23) Zhang, X.; Xia, A.; Chen, H.; Liu, Y. General and Mild NickelCatalyzed Cyanation of Aryl/Heteroaryl Chlorides with $\mathrm{Zn}(\mathrm{CN})_{2}$ : Key Roles of DMAP. Org. Lett. 2017, 19, 2118-2121.

(24) Uyeda, C.; Tan, Y.; Fu, G. C.; Peters, J. C. A New Family of Nucleophiles for Photoinduced, Copper-Catalyzed Cross-Couplings via Single-Electron Transfer: Reactions of Thiols with Aryl Halides under Mild Conditions ( $\left.{ }^{\circ} \mathrm{C}\right)$. J. Am. Chem. Soc. 2013, 135, 95489552.

(25) Fernández-Rodríguez, M. A.; Shen, Q.; Hartwig, J. F. A General and Long-Lived Catalyst for the Palladium-Catalyzed Coupling of Aryl Halides with Thiols. J. Am. Chem. Soc. 2006, 128, 2180-2181.

(26) Jones, K. D.; Power, D. J.; Bierer, D.; Gericke, K. M.; Stewart, S. G. Nickel Phosphite/Phosphine-Catalyzed C-S Cross-Coupling of Aryl Chlorides and Thiols. Org. Lett. 2018, 20, 208-211.

(27) Yin, G.; Kalvet, I.; Englert, U.; Schoenebeck, F. Fundamental Studies and Development of Nickel-Catalyzed Trifluoromethylthiolation of Aryl Chlorides: Active Catalytic Species and Key Roles of Ligand and Traceless MeCN Additive Revealed. J. Am. Chem. Soc. 2015, 137, 4164-4172.

(28) Sundermeier, M.; Mutyala, S.; Zapf, A.; Spannenberg, A.; Beller, M. A Convenient and Efficient Procedure for the PalladiumCatalyzed Cyanation of Aryl Halides Using Trimethylsilylcyanide. J. Organomet. Chem. 2003, 684, 50-55.

(29) Sundermeier, M.; Zapf, A.; Beller, M. A Convenient Procedure for the Palladium-Catalyzed Cyanation of Aryl Halides. Angew. Chem., Int. Ed. 2003, 42, 1661-1664.

(30) Burg, F.; Egger, J.; Deutsch, J.; Guimond, N. A Homogeneous Method for the Conveniently Scalable Palladium- and NickelCatalyzed Cyanation of Aryl Halides. Org. Process Res. Dev. 2016, $20,1540-1545$.

(31) Nauth, A. M.; Opatz, T. Non-Toxic Cyanide Sources and Cyanating Agents. Org. Biomol. Chem. 2019, 17, 11-23.

(32) Yu, P.; Morandi, B. Nickel-Catalyzed Cyanation of Aryl Chlorides and Triflates Using Butyronitrile: Merging Retro-Hydrocyanation with Cross-Coupling. Angew. Chem., Int. Ed. 2017, 56, 15693-15697.

(33) Mills, L. R.; Graham, J. M.; Patel, P.; Rousseaux, S. A. L. NiCatalyzed Reductive Cyanation of Aryl Halides and Phenol 
Derivatives via Transnitrilation. J. Am. Chem. Soc. 2019, 141, 1925719262.

(34) Chen, H.; Sun, S.; Liu, Y. A.; Liao, X. Nickel-Catalyzed Cyanation of Aryl Halides and Hydrocyanation of Alkynes via C-CN Bond Cleavage and Cyano Transfer. ACS Catal. 2020, 10, 13971405.

(35) Mao, J.; Jia, T.; Frensch, G.; Walsh, P. J. Palladium-Catalyzed Debenzylative Cross-Coupling of Aryl Benzyl Sulfides with Aryl Bromides: Synthesis of Diaryl Sulfides. Org. Lett. 2014, 16, 53045307.

(36) Li, Y.; Bao, G.; Wu, X. F. Palladium-Catalyzed Intermolecular Transthioetherification of Aryl Halides with Thioethers and Thioesters. Chem. Sci. 2020, 11, 2187-2192.

(37) De La Higuera Macias, M.; Arndtsen, B. A. Functional Group Transposition: A Palladium-Catalyzed Metathesis of $\mathrm{Ar}-\mathrm{X} \sigma$-Bonds and Acid Chloride Synthesis. J. Am. Chem. Soc. 2018, 140, 1014010144.

(38) Lee, Y. H.; Morandi, B. Metathesis-Active Ligands Enable a Catalytic Functional Group Metathesis between Aroyl Chlorides and Aryl Iodides. Nat. Chem. 2018, 10, 1016-1022.

(39) Bhawal, B. N.; Morandi, B. Catalytic Isofunctional ReactionsExpanding the Repertoire of Shuttle and Metathesis Reactions. Angew. Chem., Int. Ed. 2019, 58, 10074-10103.

(40) Isshiki, R.; Inayama, N.; Muto, K.; Yamaguchi, J. Ester Transfer Reaction of Aromatic Esters with Haloarenes and Arenols by a Nickel Catalyst. ACS Catal. 2020, 10, 3490-3494.

(41) Nakao, Y.; Oda, S.; Hiyama, T. Nickel-Catalyzed Arylcyanation of Alkynes. J. Am. Chem. Soc. 2004, 126, 13904-13905.

(42) Nakai, K.; Kurahashi, T.; Matsubara, S. Nickel-Catalyzed Cycloaddition of $o$-Arylcarboxybenzonitriles and Alkynes via Cleavage of Two Carbon-Carbon $\sigma$ Bonds. J. Am. Chem. Soc. 2011, 133, 11066-11068.

(43) Nakao, Y.; Yada, A.; Ebata, S.; Hiyama, T. A Dramatic Effect of Lewis-Acid Catalysts on Nickel-Catalyzed Carbocyanation of Alkynes. J. Am. Chem. Soc. 2007, 129, 2428-2429.

(44) Bhawal, B. N.; Reisenbauer, J. C.; Ehinger, C.; Morandi, B. Overcoming Selectivity Issues in Reversible Catalysis: A Transfer Hydrocyanation Exhibiting High Kinetic Control. J. Am. Chem. Soc. 2020, 142, 10914-10920.

(45) Delcaillau, T.; Bismuto, A.; Lian, Z.; Morandi, B. NickelCatalyzed Inter- and Intramolecular Aryl Thioether Metathesis by Reversible Arylation. Angew. Chem., Int. Ed. 2020, 59, 2110-2114.

(46) Ichiishi, N.; Malapit, C. A.; Woźniak, A.; Sanford, M. S. Palladium- and Nickel-Catalyzed Decarbonylative C-S Coupling to Convert Thioesters to Thioethers. Org. Lett. 2018, 20, 44-47.

(47) Brigham, C. E.; Malapit, C. A.; Lalloo, N.; Sanford, M. S. Nickel-Catalyzed Decarbonylative Synthesis of Fluoroalkyl Thioethers. ACS Catal. 2020, 10, 8315-8320.

(48) Hanson, M. G.; Olson, N. M.; Yi, Z.; Wilson, G.; Kalyani, D. Nickel-Catalyzed Coupling of Azoles with Aromatic Nitriles. Org. Lett. 2017, 19, 4271-4274.

(49) Chatupheeraphat, A.; Liao, H. H.; Lee, S. C.; Rueping, M. Nickel-Catalyzed $\mathrm{C}-\mathrm{CN}$ Bond Formation via Decarbonylative Cyanation of Esters, Amides, and Intramolecular Recombination Fragment Coupling of Acyl Cyanides. Org. Lett. 2017, 19, 42554258.

(50) Heravi, M. M.; Panahi, F.; Iranpoor, N. Nickel-Catalyzed Deoxycyanation of Activated Phenols via Cyanurate Intermediates with $\mathrm{Zn}(\mathrm{CN})_{2}$ : A Route to Aryl Nitriles. Org. Lett. 2018, 20, 27532756.

(51) Vogt, M.; de Bruin, B.; Berke, H.; Trincado, M.; Grützmacher, H. Amino Olefin Nickel(I) and Nickel(0) Complexes as Dehydrogenation Catalysts for Amine Boranes. Chem. Sci. 2011, 2, 723-727.

(52) Liu, N.; Mei, S.; Sun, D.; Shi, W.; Feng, J.; Zhou, Y.; Mei, F.; $\mathrm{Xu}$, J.; Jiang, Y.; Cao, X. Effects of Charge Transport Materials on Blue Fluorescent Organic Light-Emitting Diodes with a Host-Dopant System. Micromachines 2019, 10, 344.
(53) Levterov, V. V.; Panasyuk, Y.; Pivnytska, V. O.; Mykhailiuk, P. K. Water-Soluble Non-Classical Benzene Mimetics. Angew. Chem., Int. Ed. 2020, 59, 7161-7167.

(54) Buback, M.; Kuelpmann, A. A Suitable Photoinitiator for Pulsed Laser-Induced Free-Radical Polymerization. Macromol. Chem. Phys. 2003, 204, 632-637.

(55) Kaiser, M.; Bray, M. A.; Cal, M.; Trunz, B. B.; Torreele, E.; Brun, R. Antitrypanosomal Activity of Fexinidazole, a New Oral Nitroimidazole Drug Candidate for Treatment of Sleeping Sickness. Antimicrob. Agents Chemother. 2011, 55, 5602-5608.

(56) McCormack, P. L. Celecoxib. Drugs 2011, 71, 2457-2489.

(57) Graneto, M. J. Substituted Pyrazolyl Benzenesulfonamide for the Treatment of Inflammation. U.S. Patent 5,521,207, filed April 6, 1994, and issued May 28, 1996.

(58) Fang, X.; Yu, P.; Morandi, B. Catalytic Reversible AlkeneNitrile Interconversion through Controllable Transfer Hydrocyanation. Science 2016, 351, 832-836.

(59) Matsushita, K.; Takise, R.; Muto, K.; Yamaguchi, J. Ester Dance Reaction on the Aromatic Ring. Sci. Adv. 2020, 6, No. eaba7614. 